Article

\title{
Factors That Explain the Utilization of the Nagoya Protocol Framework for Access and Benefit Sharing
}

\author{
Gerzaín Avilés-Polanco ${ }^{1}$, David J. Jefferson ${ }^{2}$, Marco Antonio Almendarez-Hernández ${ }^{3}$ and \\ Luis Felipe Beltrán-Morales ${ }^{3, *}$ \\ 1 CONACYT-Centro de Investigaciones Biológicas del Noroeste (CIBNOR), Instituto Politecnico Nacional 195, \\ Colonia Playa Palo de Santa Rita, La Paz 23096, B.C.S., Mexico; gpolanco@cibnor.mx \\ 2 TC Beirne School of Law, University of Queensland, St Lucia, Queensland 4072, Australia; \\ d.jefferson@uq.edu.au \\ 3 Centro de Investigaciones Biológicas del Noroeste (CIBNOR), Instituto Politecnico Nacional 195, \\ Colonia Playa Palo de Santa Rita, La Paz 23096, B.C.S., Mexico; malmendarez@cibnor.mx \\ * Correspondence: lbeltran04@cibnor.mx
}

Received: 23 August 2019; Accepted: 4 October 2019; Published: 9 October 2019

\begin{abstract}
One of the primary concerns of countries with high levels of biodiversity is the conservation of species and natural environments. This prioritization is based in part on a recognition of the importance of ecosystem services, understood as the various benefits that humans derive from ecosystems, which may be developed into goods and services that are transacted in markets. The Nagoya Protocol is an international agreement whose purpose is to provide a framework under which countries can support biodiversity conservation by regulating access to native genetic materials. Such materials may be of interest to companies, organizations, and institutions for commercial, non-commercial, or both purposes. Furthermore, genetic resources constitute important inputs in numerous industries, including those in the pharmaceutical, biotechnology, botany and horticultural, agricultural, personal hygiene and cosmetics, and food and beverage sectors. The present study explores whether there is a relationship between biodiversity, the implementation of systems to protect natural areas and the quality of institutions, and the utilization of the Nagoya Protocol framework in individual countries. A Probit model was estimated to test these relationships, and a Canonical Correspondence Analysis (CCA) was conducted to identify whether the aforementioned factors explain the execution of access and benefit sharing (ABS) agreements, as measured through the lodging of Internationally Recognized Certificates of Compliance (IRCC) in the Access and Benefit-Sharing Clearing-House (ABSCH) of the Convention on Biological Diversity. The findings indicated that biodiversity conservation policies, specifically the designation of protected natural areas, are important factors that might motivate actors in Nagoya Protocol member countries to utilize the protocol system. The CCA also revealed that the quality of institution factors such as the protection of property rights, the efficiency of legal frameworks for dispute resolution, investor protection, and a low government regulation burden. also help to explain the utilization of ABS agreements.
\end{abstract}

Keywords: Nagoya Protocol; access and benefit sharing; natural protected areas; national biodiversity index; quality of institutions

\section{Introduction}

One of the primary concerns of countries with high levels of biodiversity is the conservation of species and natural environments. This prioritization is based in part on a recognition of the importance of ecosystem services, understood as the various benefits that humans derive from natural environments, which may be developed into goods and services that are transacted in markets. 
For example, microorganisms support the health of most of the earth's ecosystems and play an important role in agriculture, food production, and human health [1]. To address concerns about biodiversity conservation, the international community produced the Convention on Biological Diversity (CBD) in 1992 during the United Nations Conference on Environment and Development. The objectives of the CBD are the conservation of biodiversity, the sustainable use of its components, and the fair and equitable sharing of the benefits arising out of the utilization of genetic resources.

Subsequently, parties to the World Summit on Sustainable Development, which took place in Johannesburg in 2002, recognized the need to take additional measures to promote the fulfillment of the third objective of the CBD. Therefore, a proposal was launched to negotiate an international framework that would elaborate a system for the fair and equitable sharing of benefits derived from the utilization of genetic resources, which was embodied in the Johannesburg Plan of Implementation. After the 2002 World Summit, the Johannesburg Plan was considered and modified every two years in the biannual meetings of the Conference of the Parties to the CBD. These events took place in Kuala Lumpur (2004), Curitiba (2006), and Bonn (2008), and after each conference, statements were issued that invited parties to the CBD and other relevant stakeholders to participate in the process of the negotiation and elaboration of an international access and benefit sharing (ABS) regime. The latter of these meetings generated the Bonn Guidelines, a document that was intended to assist governments in the adoption of measures to govern ABS in their countries.

However, because the guidelines were voluntary and focused solely on the users of genetic resources, critics complained that a more complete framework for ABS was still needed, which would take into account the interests of genetic resource providers, as well as issues related to conservation and sustainable use [2]. Ultimately, during the tenth meeting of the Conference of the Parties held in Japan in 2010, the Nagoya Protocol on Access to Genetic Resources and the Fair and Equitable Sharing of Benefits Arising from their Utilization was finalized as a means to address the concerns expressed about the Bonn Guidelines [3]. The Nagoya Protocol entered into force and became binding for its members on 12 October 2014. Therefore, more than 22 years passed from the adoption of the CBD in May 1992 to the entry into force of the Nagoya Protocol in 2014. The delay may be explained by several factors, the most prominent of which was confusion surrounding the meaning and scope of the ABS provisions of the CBD. The ambiguity was such that, by 2007, only 39 of the then 189 contracting parties to the CBD had endeavored to enact domestic legislation that would implement the convention [4].

This is a surprising lack of action, given that Article 3 of the CBD declared that states have sovereignty over the biological resources located within their separate jurisdictions, in contrast to the historical situation, in which these resources were considered the "common heritage" of humankind and consequently were available without restriction. The sovereignty principle entitles CBD member countries to regulate access to their genetic resources under national law, including by mandating conditions for prior informed consent and benefit sharing [5]. This notion was expanded under the Nagoya Protocol framework, such that where there exists traditional or indigenous knowledge associated with genetic resources, countries should consider the interests and rights of the communities that hold this knowledge in the national framework and protocols for ABS.

The inclusion of traditional knowledge within the ambit of the ABS regime means that local and indigenous communities should participate in the sharing of both monetary and non-monetary benefits derived from the utilization of resources about which they possess knowledge (Article 12). Meanwhile, where genetic resources for which there is no traditional knowledge are accessed and utilized, prior informed consent must still be obtained from, and benefit sharing agreements negotiated and signed with, the providers of these resources. Depending on the nature of the source from which the resources are obtained, providers may include national or sub-national government authorities, public or private institutions, or private landowners.

By creating a framework for ABS, the Nagoya Protocol aims to curb the extraction and/or commercialization of genetic material and traditional knowledge by firms and other institutions that are located in countries in which genetic resources are utilized without the consent of the provider(s) 
in the country from which the resources are obtained [6]. Furthermore, the protocol aims to protect the interests of indigenous and local communities, by recognizing the importance of their traditional knowledge to the historical and ongoing development and utilization of genetic resources. The Nagoya Protocol also endeavors to rectify past injustices, implicitly acknowledging that, for decades, industrial interests in a variety of economic sectors have profited exclusively from the commercial exploitation of genetic resources and associated traditional knowledge, without sharing benefits with resource and knowledge providers [5].

Therefore, one of the primary contributions that the Nagoya Protocol makes is to provide a standardized regulatory framework for how users of genetic resources may access and utilize these resources and associated traditional knowledge, with the obligation that any benefits derived from utilization be shared fairly and equitably with the providers. These ABS obligations may be conceptualized in at least three ways: (1) as a means to correct the social and economic injustices associated with the global intellectual property system; (2) as a tool for economic development, through the capture of benefits derived from the commercialization of products created through the use of genetic resources; and (3) as an incentive for the conservation of biodiversity [7]. Parties to the Nagoya Protocol are required to guarantee, through national legislation and enforcement regimes, that the ABS system is actualized and made effective. This indicates that the quality of domestic institutions is fundamental to ensuring that the Nagoya Protocol framework is implemented and that parties comply with its requirements.

Essential institutions that the protocol requires member countries to designate include a National Focal Point and a Competent National Authority (Article 13). The former institution is responsible for making information available to applicants seeking access to genetic resources and associated traditional knowledge, as well as for establishing procedures for users to obtain prior informed consent and to negotiate mutually agreed terms, including for benefit sharing. Meanwhile, Competent National Authorities are responsible for granting access, or, where applicable, issuing written evidence that access requirements have been met. Both institutions are also charged with advising stakeholders on applicable procedures and requirements for obtaining prior informed consent and entering into mutually agreed terms.

For its part, Article 15 of the Nagoya Protocol stipulates that contracting parties must take appropriate, effective, and proportionate legislative, administrative, or policy measures to ensure that genetic resources utilized within their respective jurisdictions have been accessed in accordance with prior informed consent and that mutually agreed terms have been established. These provisions mean that it is crucial that countries have the appropriate institutional mechanisms in place to make the national ABS system effective. The difference in the quality of institutions has been shown to constitute one of the principal causes of gaps in economic development between countries [8]. Specifically, weak institutions may discourage investment and thereby complicate the development of a given country, where potential investors would need to spend excessive amounts of time and resources to protect their private property or to enforce contractual obligations. In this way, institutions can inspire investor confidence by guaranteeing a basic level of security and efficacy in the protection of property rights and the enforcement of contracts [9]. Therefore, it is expected that countries with higher quality institutions will offer more favorable conditions for the effective implementation of ABS systems.

Notwithstanding its laudable goals, five years after the entry into force of the Nagoya Protocol, there are still many unanswered questions about whether the ABS framework that the protocol creates is actually effective. For instance, has the uptake of the Nagoya Protocol system for ABS been more successful in countries with relatively high levels of biodiversity, where it might be expected that genetic resources would be accessed more frequently? Does the existence of biodiversity conservation policies-specifically those designed to create protected natural areas-explain the relative prevalence of ABS agreements? Does the quality of the institutions in a given country-measured through indices of property rights, efficiency of the legal framework for dispute resolution, the existence of protections 
for investors, and the relative burden of government regulation-explain the utilization of ABS agreements by actors interested in accessing genetic resources and associated traditional knowledge?

\section{Background}

Since the entry into force of the Nagoya Protocol in 2014, there has been much scholarly interest in how its framework for access and benefit sharing might affect the interests of various stakeholders, including governments, scientists, commercial entities, and indigenous and local communities. With the aim of identifying trends in research on the Nagoya Protocol since the date of its entry into force, we conducted a brief bibliometric analysis utilizing the Web of Science and Clarivate Analytics databases. We were particularly interested in journal articles and book chapters that were indexed in the Journal Citation Reports as an indicator of publication quality and impact. The searches included publications that were released from October 2014 to August 2019.

Using the initial search term of "access and benefit sharing" without any time restriction identified 2415 articles/book chapters in Web of Science. Meanwhile, a search for the term "Nagoya Protocol" without any time restriction yielded 176 publications in Web of Science. When we made the searches more precise by combining both terms and limiting the timeframe to the period of October 2014 to August 2019, we found only 28 results. These findings enabled the identification of scientific publications that could contain critical reflections, case studies, proposals, or experiences related to the implementation of ABS frameworks after the entry into force of the Nagoya Protocol. Figure 1 shows the distribution of results by discipline.

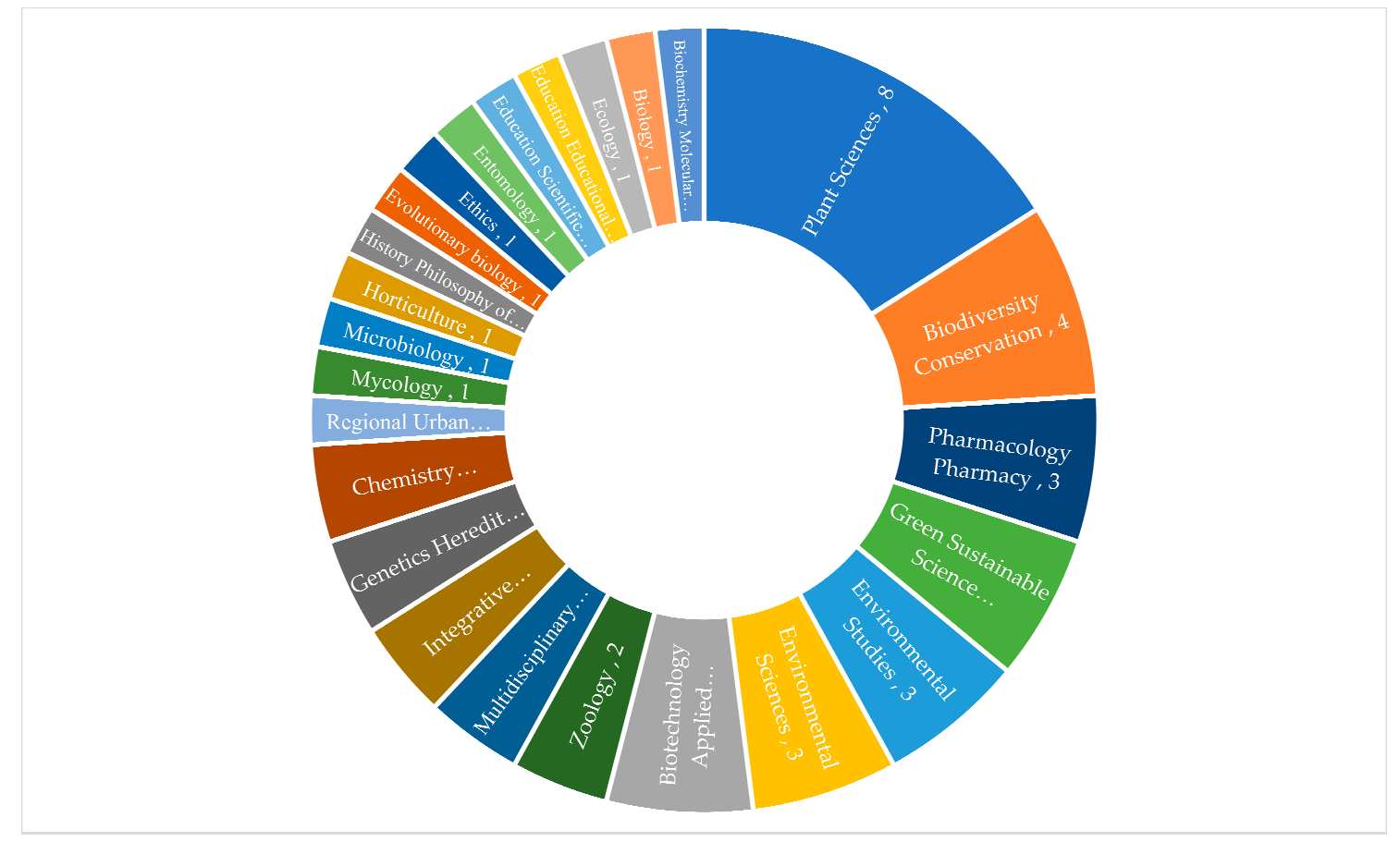

Figure 1. Distribution of publications about the Nagoya Protocol and access and benefit sharing by scientific discipline for the period of October 2014 to August 2019. Source: Authors' elaboration.

The distribution of publications by scientific discipline reveals the interdisciplinary nature of the use, management, and conservation of genetic resources, and the diversity of actors interested in systems of fair and equitable benefit sharing for the utilization of these resources and associated traditional knowledge. The majority of the studies were in the domains of plant sciences, biodiversity conservation, pharmacology/pharmacy, green/sustainable science and technology, biotechnology and applied microbiology, and environmental sciences and studies. While some of this research had a global focus, most of the studies had a regional or local scope. 
Similarly, some of the most prominent critical analyses of the Nagoya Protocol that have been conducted to date have focused on particular countries or regions, including Pacific Island nations [10], Germany and the European Union [11], French Guiana [12], and Malaysia [13]. In contrast, few studies have addressed the implementation of the Nagoya Protocol system for ABS on a global scale. One exception to this trend is the research by [14], who conducted a survey with administrators working in 222 botanical gardens across 46 countries. The results of this study indicated that many survey respondents were not yet familiar with the concept of access and benefit sharing or the Nagoya Protocol.

Although interdisciplinary in nature, the existing literature shares some common criticisms of the Nagoya Protocol regime, including those in relation to the definition and scope of its ABS terms [15-17] and other areas of ambiguity in certain concepts and provisions. For instance, prior studies have highlighted the uncertainty that exists over how to treat the utilization of genetic sequence data obtained from genetic resources, especially for resources collected historically, prior to the entry into force of the CBD and the Nagoya Protocol. Often, such data may be downloaded directly from online databases, without the need for-and in some instances, the possibility of-direct contact with genetic resource providers.

In other words, it has been suggested that the Nagoya Protocol system for ABS could already be obsolete where genetic resources are "dematerialized," a phenomenon that renders the access of physical materials irrelevant [7]. Emerging technologies, including those in the field of synthetic biology, allow for the reconstruction of a particular genetic resource using digitized genetic information, which is electronically transferable without the need to obtain the original, tangible resource [7]. This undermines the protocols of the contemporary ABS regime, which presuppose negotiations between a provider and a user of a physical object.

Scholars have also expressed concerns about the possibility that regimes designed to implement the Nagoya Protocol at the national level could impede global access to genetic materials. It has been noted, for instance, that the exchange of genetic materials between research institutions plays a fundamental role in scientific development and technology transfer, even where commercialization is not the end goal [13]. Critics of the Nagoya Protocol system argue that restrictions on the transfer of genetic material and associated sequence data could affect basic research related to biodiversity conservation and the application of research findings for the purposes of environmental monitoring, biocontrol, and food safety [17]. Others worry about the potential bureaucratic burden associated with obtaining Internationally Recognized Certificates of Compliance (IRCC) and registering these IRCCs in the Access and Benefit Sharing Clearinghouse (ABSCH) for researchers who access native genetic resources [18].

Furthermore, researchers and organizations that conduct biocontrol activities have reported difficulty in complying with the requirements of the Nagoya Protocol, as well as with receiving appropriate responses from National Focal Points and Competent National Authorities [19]. To address this issue, a variety of best practice guides and manuals have been generated to support due diligence in meeting the ABS requirements that the Nagoya Protocol mandates. Nevertheless, the implementation of the Nagoya Protocol has still been complicated by a general lack of knowledge about the ABS system on the part of the users and providers of genetic materials [14]. This has led scholars, including [20], to propose frameworks to assist in the negotiation of ABS agreements, particularly where the proposed utilization of the genetic resources in question is non-commercial in nature.

Several significant obstacles also must be overcome to ensure that ABS systems are implemented in ways that support the effective transfer of traditional knowledge associated with genetic resources. These may include the need to reconcile the customary norms of indigenous legal systems for the circulation of traditional knowledge with Western legal concepts of ownership and proprietary rights. Furthermore, it is critical to avoid the dilution or loss of traditional knowledge in ABS transactions. To mitigate this possibility, some countries have instituted national registries or databases for the documentation of traditional knowledge, although these systems may be controversial due to the implicit need to translate indigenous ways of knowing the world into statist bureaucratic structures. 
Another important point is that ABS regimes should not be viewed as a panacea, given that benefit sharing alone is not a sufficient means to provide reparations for historical and ongoing injustices committed against indigenous peoples. For this reason, it is important to promote the legal recognition of indigenous peoples' rights in national constitutional and legislative frameworks alongside the implementation of laws based on the Nagoya Protocol [21]. Indeed, as some scholars have already recognized, it is questionable whether the full realization of ABS pursuant to the Nagoya Protocol would actually reduce global injustice, given that the increased mining of genetic resources by actors from countries in the global North could produce negative effects on the biodiversity and cultural heritage of the global South [22].

Notwithstanding these concerns, researchers across the world are beginning to utilize the Nagoya Protocol framework. As of 23 August 2019, 329 IRCCs had been lodged in the ABSCH for non-commercial ABS agreements executed in countries around the world. The terms of these contracts covered the utilization of genetic resources for purposes including academic research, preservation, and conservation. The majority of users that were named as parties to these 329 ABS agreements were universities, research centers, museums, and zoos, while in some agreements, access to genetic material was granted directly to individuals, including researchers and postgraduate students. These early results demonstrate that the Nagoya Protocol could provide a governing framework under which international biodiversity research might be effectively conducted [1].

It is also important to note that some of the countries classified as "megabiodiverse"-a label that refers to any one of a group of 17 nations that harbor the majority of Earth's species and high numbers of endemic species - have already begun to implement national regimes based on the Nagoya Protocol. One example of this phenomenon is found in Mexico, where the relevant national authority recently granted a permit based on an ABS agreement concluded between an international cosmetic company and a civil society organization known as the Women and Environment, Rural Production Society located in the state of Querétaro. The terms of this agreement authorized researchers to collect forest biological resources in exchange for benefits including training and technology transfer. The agreement also provided the creation of a biodiversity conservation plan for the area where the genetic materials were accessed, job creation for local communities, and recognition of the geographical origin of the genetic material in the event that a product based on this resource was commercialized.

While megabiodiverse countries may have a greater stake in the kind of legal protection that the Nagoya Protocol offers, in order to be fully realized, the Nagoya framework should also be adopted by countries that are not classified as megabiodiverse. This is because less biodiverse countries are often where the utilization of genetic resources occurs, and because these countries house the primary markets in which products derived from genetic resources and associated traditional knowledge are commercialized. If the Nagoya Protocol was adopted globally, at least in theory, the interests of the providers of genetic resources and related traditional knowledge would be protected in jurisdictions throughout the world.

A comparison of the genetic resources that may potentially be available in different countries is facilitated by Figure 2, which shows the relative biodiversity of 159 countries, as designated by the National Biodiversity Index of the CBD [23]. This index is based on estimates of the biological abundance and endemism of four classes of terrestrial vertebrates and vascular plants. Index values vary between one (Indonesia) and zero (Greenland). As can be seen in Figure 2, the majority of the most biodiverse nations on Earth are developing countries located in the global South, while in general, the least biodiverse countries constitute the primary users of genetic resources. Notable exceptions to this trend include Australia, China, and the United States. 


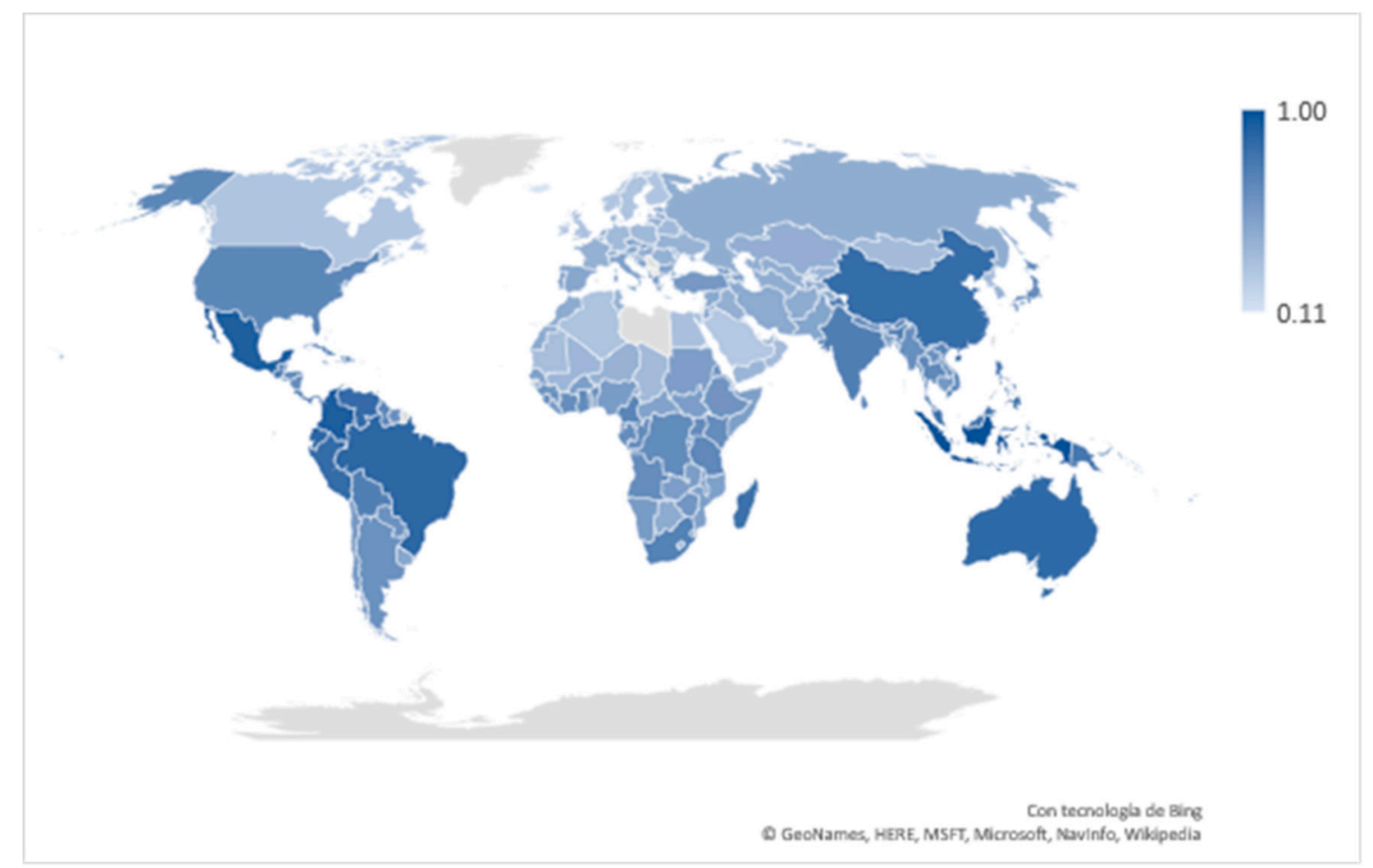

Figure 2. National Biodiversity Index. Source: Authors' elaboration, based on the National Biodiversity Index of the Convention on Biological Diversity.

Of the 196 member states of the United Nations, 58\% have ratified the Nagoya Protocol. According to the CBD registry, of the ten most biodiverse countries on Earth, only six (Indonesia, Mexico, Ecuador, Peru, Venezuela, and China) had joined the Protocol as of August 2019. Meanwhile, five of the least biodiverse countries (Qatar, Kuwait, Finland, Norway, and Sweden) were members of the Nagoya Protocol as of the same date.

Table 1 shows the number of registered IRCCs per year across all signatories to the Nagoya Protocol.

Table 1. Internationally Recognized Certificates of Compliance (IRCC).

\begin{tabular}{cccccccc}
\hline & \multicolumn{7}{c}{ Year } \\
\cline { 2 - 8 } & $\mathbf{2 0 1 4}$ & $\mathbf{2 0 1 5}$ & $\mathbf{2 0 1 6}$ & $\mathbf{2 0 1 7}$ & $\mathbf{2 0 1 8}$ & $\mathbf{2 0 1 9}$ & Total \\
\hline Number of IRCCs & 0 & 1 & 50 & 70 & 192 & 251 & 564
\end{tabular}

* Data as of 23 August 2019. Source: authors' elaboration, based on information from the Convention on Biological Diversity and the Nagoya Protocol. Available at: https://absch.cbd.int/.

As of August 2019, the ABSCH of the CBD [24] had registered a total of 564 IRCCs from all Nagoya Protocol member countries. Of these, 35\% of the IRCCs registered were for commercial purposes, and $64 \%$ were for non-commercial purposes, which included academic research and conservation studies. Finally, a mere $1 \%$ of the IRCCs were registered as non-commercial, with the possibility of later conversion to commercial agreements.

To obtain an IRCC, it is necessary that an ABS agreement be executed between the providers of the genetic resources and any associated traditional knowledge, and the users of this subject matter. The Nagoya Protocol framework requires that ABS agreements contain mutually agreed terms (MAT) that account for how any benefits derived from the prospective commercialization of products based on the resources accessed will be shared with the providers. Benefits may be monetary (e.g., royalties, upfront, milestone, or licensing fees) and/or non-monetary (e.g., training for indigenous or local provider communities, technology transfer, and infrastructure). The Nagoya Protocol stipulates that 
MAT should ensure the greatest possible benefit to providers and users alike, recognizing that the basis of negotiations between the parties is the value assigned to the genetic resources and traditional knowledge, and the degree of access granted to this subject matter [24].

Figure 3 presents a network map derived from the 564 IRCCs registered in the ABSCH. The terms or keywords were organized using Cytoscape open source software [25]. All information about the IRCCs analyzed was obtained directly from the ABSCH.

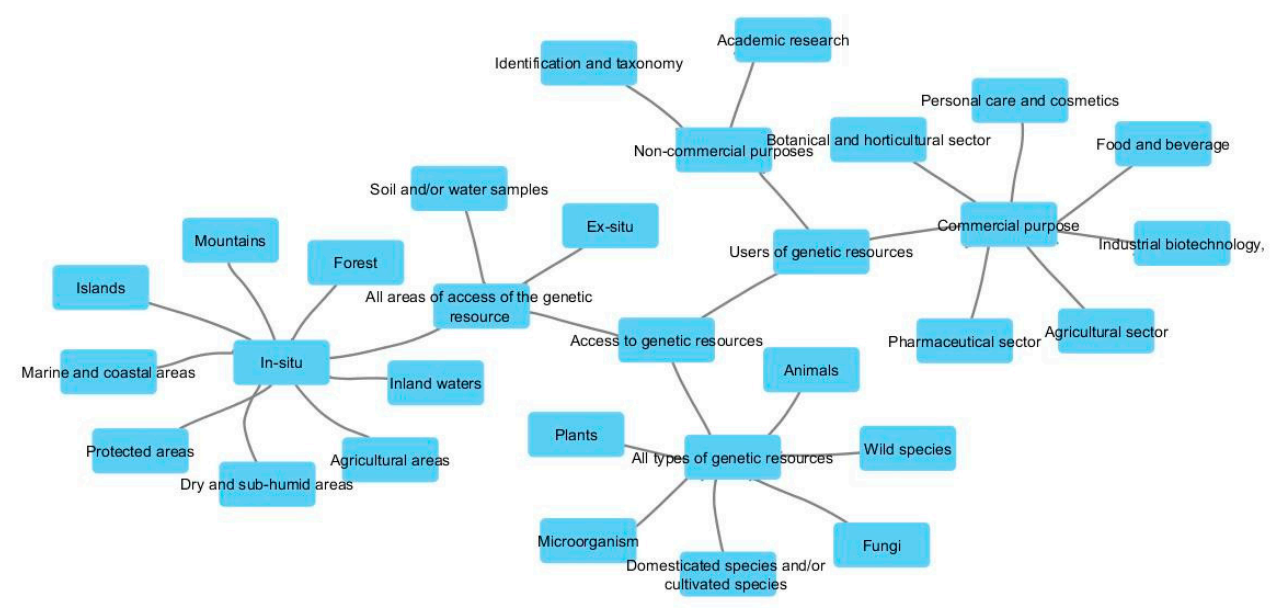

Figure 3. Network Map of Key Terms Contained in the 564 Internationally Recognized Certificates of Compliance (IRCC). Source: Authors' elaboration, based on information from the Convention on Biological Diversity and the Nagoya Protocol.

The network map displayed in Figure 3 graphically represents all IRCCs that were publicly available as of August 2019. This map illustrates how the various IRCCs are connected to each other, with each peripheral term linked to one or more central terms or nodes. This map allows the viewer to understand the types of genetic resources that are accessed, the location from which they are obtained, and the purposes of accessed resources. The network map also presents a hierarchical structure based on three essential nodes corresponding to (1) the location of access to genetic resources, (2) the type of genetic resources, and (3) the users of genetic resources.

In the location node, two types of access are identified, namely ex-situ and in-situ. The latter type of location includes natural protected areas, marine and coastal areas, islands, forests, mountains, and agricultural areas. In the type of resources node, the terms microorganisms, fungi, wildlife, plants, animals, domesticated, and/or cultivated species are identified as common classes of genetic resources. Finally, the third node, users, identifies users with commercial purposes as those situated in the biotechnology, pharmaceutical, botany and horticultural, agricultural, personal hygiene and cosmetics, and food and beverages sectors. Meanwhile, non-commercial users include those whose work centers on academic research and identification, and taxonomy.

Of the 117 countries that were members of the Nagoya Protocol as of August 2019, IRCCs had been registered for the utilization of genetic resources in only 16 countries. The vast majority of the IRCCs lodged in the ABSCH were from India, which accounted for $69 \%$ of the total. Table 2 presents the distribution of IRCCs by country, as well as the number and extent of protected natural areas, the National Biodiversity Index ranking, the Global Competitiveness Index ranking, and the biodiversity conservation expenditure for each of the 16 countries with registered IRCCs. 
Table 2. Number of IRCCs; Number and Size of Natural Protected Areas and the Biodiversity Index by Country.

\begin{tabular}{|c|c|c|c|c|c|c|}
\hline Country & IRCC & $\begin{array}{c}\text { Protected } \\
\text { Natural } \\
\text { Areas }\end{array}$ & $\begin{array}{c}\text { Protected } \\
\text { Natural Area } \\
\text { Extension } \\
\left(\mathbf{k m}^{2}\right)\end{array}$ & $\begin{array}{c}\text { National } \\
\text { Biodiversity } \\
\text { Index }\end{array}$ & $\begin{array}{l}\text { Conservation } \\
\text { Expenditure } \\
\text { (Millions of } \\
\text { Dollars) }\end{array}$ & $\begin{array}{c}\text { Institution } \\
\text { Quality } \\
\text { Index }\end{array}$ \\
\hline India & 220 & 495 & 154,508 & 0.732 & 102.14 & 4.4 \\
\hline France & 153 & 1521 & 84,505 & 0.423 & Not available & 4.8 \\
\hline Spain & 43 & 328 & 42,402 & 0.486 & Not available & 4.1 \\
\hline Kenia & 38 & 68 & 45,473 & 0.643 & 12.22 & 3.8 \\
\hline Vietnam & 28 & 54 & 9953 & 0.682 & 11.89 & 3.8 \\
\hline South Africa & 28 & 405 & 66,454 & 0.714 & 101.21 & 3.8 \\
\hline Panama & 19 & 31 & 15,474 & 0.793 & 44.96 & 3.8 \\
\hline Mexico & 8 & 212 & 183,075 & 0.928 & 331.31 & 3.2 \\
\hline Belarus & 7 & 903 & 13,043 & 0.368 & 1.33 & - \\
\hline Bulgaria & 3 & 127 & 5001 & 0.493 & 0.16 & 3.5 \\
\hline $\begin{array}{c}\text { Lao People's } \\
\text { Democratic } \\
\text { Republic }\end{array}$ & 5 & 17 & 27,563 & 0.615 & 20.3 & 4 \\
\hline Dominican Republic & 2 & 45 & 15,545 & 0.661 & 3.23 & 3 \\
\hline Guatemala & 2 & 42 & 21,668 & 0.744 & 11.57 & 3.3 \\
\hline Peru & 5 & 35 & 68,203 & 0.843 & 42.08 & 3.2 \\
\hline Uruguay & 2 & 13 & 477 & 0.487 & 7.13 & 4.6 \\
\hline Malta & 1 & 7 & 3 & $\begin{array}{c}\text { Not } \\
\text { available }\end{array}$ & Not available & 4.5 \\
\hline
\end{tabular}

Source: Authors' elaboration, based on information from the Convention on Biological Diversity and the Nagoya Protocol. Note: the quality of institutions index is based on a scale of 1 to 7 , such that, as the numbers increase, so too does the quality of institutions of a given country.

As can be seen in Table 2, India is the country for which the greatest number of IRCCs have been lodged in the ABSCH, of which $77 \%$ were for commercial ABS agreements and $22 \%$ were for non-commercial agreements. The country with the second highest number of IRCCs filed was France, with 153 records, all of which were for non-commercial ABS agreements. It is notable that IRCCs from France only began to be registered in March 2019, which indicates a rapid implementation of the Nagoya Protocol system in that country. Interestingly, of the countries for which IRCCs have been filed in the $\mathrm{ABSCH}$, France is ranked second to last according to the National Biodiversity Index, but first in terms of the quality of institutions and number of protected natural areas, and third in terms of protected natural area extension. Meanwhile, India is positioned in second place for the quality of institutions, extension of protected natural areas, and conservation expenditure. For comparison, Mexico is ranked first according to the National Biodiversity Index, extension of protected natural areas, and conservation expenditure, but as of August 2019, only eight IRCCs had been filed for that country.

These results indicate that the countries with the largest numbers and extensions of protected natural areas, as well as with the greatest expenditures on biodiversity conservation and the highest quality of institution rankings, have also registered the most IRCCs. This suggests that, among the countries in which IRCCs have been lodged in the ABSCH, those with the most developed policy and institutional frameworks for biodiversity conservation and the utilization of genetic resources have implemented the Nagoya Protocol most fully. While this observation may appear tautological, the key point is that it appears that the ratification of the Nagoya Protocol and the enactment of national legislation to implement the protocol alone are not sufficient actions to encourage domestic actors 
to utilize the ABS system. Instead, complementary policy and institutional frameworks enable the Nagoya Protocol to be effective at the national level.

\section{Specification of the Probit Model}

The study is based on information contained in IRCCs lodged in the ABSCH by 16 of the 117 member countries of the Nagoya Protocol during the period of January 2014 to August 2019. The specification of the dependent variable is expressed as follows: $Y_{i} \in(0,1)$ with cross-sectional data. Values of 1 are assumed for countries with registered IRCCs and 0 for countries without registered IRCCs. The proposed model considers that the individual characteristics of each country will explain the probability that it will utilize the Nagoya Protocol framework, as manifested in the registration of IRCCs. In this way, the model explains the variation in the utilization of the Nagoya system according to the following representation of the Probit model:

$$
Y_{i}=\alpha+\beta^{\prime} X_{i}+\varepsilon_{i}
$$

Therefore, the probability of utilizing the Nagoya Protocol framework follows the distribution

$$
y_{i} \mid X_{i} \sim \operatorname{Normal}\left(\alpha+\beta^{\prime} X_{i}+\varepsilon_{i} ; \sigma_{\beta}^{2}\right)
$$

where $y_{i}$ is the probability of utilizing the Nagoya Protocol framework; $\beta$ is a vector of unknown parameters; and $X_{i}$ is the matrix of characters particular to each country, in relation to biodiversity, the size of protected natural areas, and the quality of institutions variable confirmed by the average indices of property rights, efficiency in the legal framework for dispute resolution, strength of investor protection, and the relative burden of government regulation. Finally, $\varepsilon_{i}$ is the residual component.

The probability model is expected to find that countries with higher levels of biodiversity have a greater probability of utilizing the Nagoya Protocol framework, compared to those with less diversity. Likewise, it is expected that countries with well-developed biodiversity conservation policies, represented through the establishment of protected natural areas and the relatively larger size of these areas, will have a greater probability of utilizing the Nagoya system than countries with fewer conservation policies or smaller protected natural areas. Furthermore, it is expected that countries with higher quality institutions, as measured by the indicator "first pillar institutions" of the World Bank [18], (namely this composite indicator is derived from the following indicators: (a) property rights; (b) intellectual property protection; (c) diversion of public funds; (d) public trust of politicians; (e) irregular payments and bribes; (f) judicial independence; (g) favoritism in decisions of government officials; (h) wastefulness of government officials; (i) burden of government regulation; (j) efficiency of the legal framework in settling disputes; $(k)$ efficiency of the legal framework in challenging regulations; (l) transparency of government policymaking; (m) business costs of terrorism; (n) business costs of crime and violence; (o) organized crime; $(\mathrm{p})$ reliability of police services; $(\mathrm{q})$ ethical behavior of firms; (r) strength of auditing and reporting standards; (s) efficacy of corporate boards; ( $\mathrm{t}$ ) protection of minority shareholders' interests; and ( $\mathrm{u}$ ) strength of investor protection), will be more likely to utilize the Nagoya Protocol framework.

It should be mentioned that factors including the richness of local traditional knowledge and the level of development of work in synthetic biology in the national scientific sector could also affect the likelihood that actors in a given country might utilize the Nagoya Protocol ABS system. Nevertheless, these variables were not included in the Probit model because global level indicators have not yet been created to describe these factors.

\section{Specification of the Canonical Correspondence Analysis}

The Canonical Correspondence Analysis (CCA) arose out of environmental studies, particularly in the discipline of ecology, as a multivariate statistical method that conveys information about sampling stations, communities of biological species, and environmental parameters. This statistical treatment 
was based on the pioneering work of [26], and it corresponds to the category of direct gradient analysis. The employment of this method in the present work constitutes an adaptation for use in socio-environmental analysis. No precedents were found for the application of CCA in the literature on the Nagoya Protocol. The CCA is conceived as a variant of correspondence analysis (CA), and it aims to locate the subspaces that best explain biological data under the condition that they are directly related to environmental variables. Since CCA is an extension of CA, what is sought are the dimensions of the subspace by regression using environmental variables (explanatory variables) and species data (multiple response variables). In the regression, the general linear model can be used, which is composed of traditional regression methods or extended and improved models, such as the generalized linear model (GLM) and the generalized additive model (GAM).

For example, in communities of species conditioned to environmental differences, variations in the composition of species or their relative abundance and richness can be found, while accounting for consistency and calculating the predictability of that variation. However, individual changes in the composition of species communities are gradual and related to environmental factors such as the average soil moisture, competition between species for nutrients, temperature, etc. If the samples are ordered by axes (in two or three imaginary axes) and humidity, temperature, or nutrients are specified as environmental factors, they can be defined as a moisture gradient, a nutrient gradient, and a temperature gradient.

The CCA methodology has been used in pioneering research in the field of economics, where it has not only combined environmental variables, but also incorporated social and economic variables [27,28]. If, in the context of a CA, there is a matrix $\mathrm{n} \times \mathrm{m}, \mathrm{Y}\left(y_{i k} \geq 0\right)$, in CCA, this matrix is a matrix of multivariate response variables, and it is related to a second matrix, $n \times p$, with explanatory variables ( $Z$ columns). This method comprises CA and regression analysis. In the regression analysis, the response variables and the explanatory variables must correspond to the same group of sites. The second group of variables can be quantitative, binary, or nominal. In summary, one of the main purposes of CCA is to generate an ordination diagram (factorial plan) that indicates the pattern of variation of the communities of species explained by the relationship it has with environmental factors. The reason for which CCA is used is because the best fit to the main axis (the line that best fits is designated as the main axis) is sought in a restricted part of the space and not in the total data space.

A restriction of the CCA method is that all response variables are required to be transformed on the same scale, which is usually done in terms of logarithms. Since the logarithm of 1 is zero and the logarithm between 0 and 1 provides negative values, the CANOCO 5.1 statistical package (Ithaca, NY, USA), which is one of the optimal programs with which to perform CCA analysis, provides a flexible transformation formula [29]:

$$
y^{\prime}=\log (A \cdot y+C)
$$

The values of $A$ and $C$ must be specified to later transform the values of (y), obtaining a result of (y) that is always greater than or equal to zero. For their part, the environmental variables are standardized; that is, with a mean of zero and a variance of one. In the present study, the use of CCA can be analogized to its utilization in the discipline of ecology as follows: the sampling stations are the countries; the species communities are the types of IRCCs (i.e., (1) commercial, (2) commercial-non-commercial, and (3) non-commercial); and the environmental variables are composed of the quality of institutions indicators, as measured by the indicator "first pillar institutions" of the World Bank. These quality of institutions variables specifically include property rights, the efficiency of the legal framework for dispute resolution, protection for investors, the relative burden of government regulation, and biodiversity conservation policies, measured by the extension of protected natural areas and the biodiversity index of each country.

Therefore, the CCA model is as follows:

$$
I R C C \sim \text { active(biodiversity }+ \text { extention of protected natural areas }+ \text { quality of institutions) }
$$


To perform the CCA analysis, countries that have registered IRCCs in the ABSCH of the Nagoya Protocol were selected. These included India, France, Spain, Kenya, South Africa, Vietnam, Panama, Mexico, Lao Peoples' Democratic Republic, Peru, Bulgaria, Belarus, the Dominican Republic, Guatemala, Uruguay, and Malta. Biodiversity was measured by the CBD National Biodiversity Index, the extent of protected areas was measured in $\mathrm{km}^{2}$, and the quality of institutions was measured by averaging the four variables selected from the World Bank Global Competitiveness Index that are described in Table 3.

Table 3. Description of Variables Used in the Model.

\begin{tabular}{|c|c|c|}
\hline Variable & Variable Description & Source \\
\hline abs & $\begin{array}{l}\text { Dichotomous variable that takes the value of one (1) } \\
\text { for countries that have at least one IRCC and zero (0) } \\
\text { for countries with no IRCCs }\end{array}$ & $\begin{array}{l}\text { Access and Benefit-Sharing } \\
\text { Clearing-House of the Nagoya } \\
\text { Protocol: https://absch.cbd.int/ }\end{array}$ \\
\hline ide & National Biodiversity Index & $\begin{array}{c}\text { Convention on Biological } \\
\text { Diversity, available at https: } \\
\text { //www.cbd.int/gbo1/annex.shtml }\end{array}$ \\
\hline eanp & Extension of protected natural areas $\left(\mathrm{km}^{2}\right)$ & $\begin{array}{c}\text { Convention on Biological } \\
\text { Diversity, available at https: } \\
\text { //www.cbd.int/gbo1/annex.shtml }\end{array}$ \\
\hline Institutions & $\begin{array}{l}\text { Average of four variables from the Global } \\
\text { Competitiveness Index of the World Bank: } \\
\text { (1) Property rights, (2) efficiency of the legal } \\
\text { framework for dispute resolution, (3) investor } \\
\text { protection, and (4) government regulation burden }\end{array}$ & $\begin{array}{l}\text { World Bank, available at } \\
\text { http://reports.weforum.org/ } \\
\text { global-competitiveness-index- } \\
\text { 2017-2018/competitiveness- } \\
\text { rankings/\#series=GCI.A.01.01.01 }\end{array}$ \\
\hline
\end{tabular}

Source: Authors' elaboration.

\section{Description of the Data}

To estimate the Probit model, information from the 117 countries that are parties to the Nagoya Protocol was used. The data related to the number of IRCCs registered in the ABSCH was obtained in August 2019. A description of the variables used is displayed in Table 3.

Table 4 shows the descriptive statistics of the variables in logarithms, which were selected for the regression analysis.

Table 4. Descriptive Statistics of the Variables.

\begin{tabular}{cccccc}
\hline Variable & Mean & $\begin{array}{c}\text { Standard } \\
\text { Deviation }\end{array}$ & Minimum & Maximum & $\begin{array}{c}\text { Number of } \\
\text { Observations }\end{array}$ \\
\hline abs & 0.10 & 0.30 & 0 & 1 & 117 \\
\hline ide & -0.62 & 0.30 & -1.66 & 0 & 100 \\
\hline institutions & 0.27 & 0.12 & 0 & 0.44 & 49 \\
\hline eanp & 3.94 & 1.15 & 0.47 & 5.99 & 106 \\
\hline property rights & 0.64 & 0.11 & 0.22 & 0.81 & 47 \\
\hline $\begin{array}{c}\text { government regulation burden } \\
\text { efficiency of the legal framework in } \\
\text { dispute resolution }\end{array}$ & 0.53 & 0.10 & 0.21 & 0.72 & 47 \\
\hline investor protection & 0.73 & 0.14 & 0.19 & 0.77 & 43 \\
\hline
\end{tabular}

Source: Authors' elaboration. Note: the variables are expressed in logarithms, except abs, which corresponds to a binary variable. 
To determine the level of biodiversity and the existence of conservation-oriented policies as measured based on the protection of natural areas, as well as the quality of institution factors such as property rights, the government regulation burden, the efficiency of the legal framework for dispute resolution, and the strength of investor protection in the utilization of the Nagoya Protocol framework, two matrices were generated. $Y=\left[y_{i j}\right]$, where $i=16$, represents the number of countries that have lodged IRCCs in the ABSCH and $j=3$ represents the type of agreement covered by the IRCC. $X=\left[x_{i j}\right]$, where $i=16$. countries and $j=6$ represents the variables biodiversity, extension of protected natural areas, property rights, the government regulation burden, the efficiency of the legal framework for dispute resolution, and the strength of investor protection.

\section{Results}

The regression results show the variation in the probability of utilizing the Nagoya Protocol framework as represented by the registration of IRCCs, explained by the logarithm of the National Biodiversity Index, the size of natural protected areas, and the date of adherence to the protocol. The econometric estimation was performed in STATA (version 15.1, 4905 Lakeway Drive College Station, Texas 77845 USA) and its results are shown in Table 5.

Table 5. Results of the Probit Model.

\begin{tabular}{cccc}
\hline Variable & Coefficient & Standard Error & Value Z \\
\hline logide & $8.48^{*}$ & 3.14 & 2.70 \\
\hline loginstituciones & $9.82{ }^{*}$ & 4.39 & 2.24 \\
\hline logeanp & 0.47 & 0.56 & 0.83 \\
\hline Constant & -4.37 & 3.00 & -1.45
\end{tabular}

Log likelihood $=-8.688537$. Number of obs. $=44$, Prob $>$ chi2 $=0.0005$. Pseudo $R^{2}=0.50$. $\left.{ }^{*}\right)$ indicates significance at the $95 \%$ confidence interval. Authors' elaboration.

The measure of goodness of fit (pseudo $\mathrm{R}^{2}$ ) of the model indicates that it explains $50 \%$ of the variance in the utilization of the Nagoya Protocol framework in a given country, according to the explanatory variables. This is a typical percentage in models that use cross-sectional data. All of the coefficients show a positive association between greater biological diversity and the utilization of the Nagoya Protocol framework through the registration of IRCCs; that is, a higher value in the National Biodiversity Index is associated with a greater probability that actors in a given country will make use of the national ABS regime. A higher institutional quality, measured as the average of the indices of property rights, relative burden of government regulation, efficiency of the legal framework for dispute resolution, and strength of investor protection, is associated with an increase in the probability of utilizing the Nagoya Protocol system. The protected natural area size variable was not statistically significant at the usual levels of statistical significance.

The results of the CCA were significant as a whole according to the Monte Carlo test with 1000 permutations [trace $=0.5637 ;$ F-ratio $=3.6243 ;$-value $=0.01898$, occurrences $=20$, Variance Inflation Factor (VIF < 5)] and there were no collinearity issues, since all of the values of the variance inflation factor were less than 5. The first two axes offered a good solution to the utilization of the Nagoya Protocol framework through the registration of IRCCs. This is because the variability present in the data on the number of filings (inertia $=0.728$ ) explained $100 \%$ of the relationship between the existence of IRCCs and the biodiversity, conservation, and quality of institutions variables in the first two axes, as well as $78.4 \%$ of the variance in IRCCs (Table 6). 
Table 6. Canonical Correspondence Analysis (CCA) results on the relationship between the filing of IRCCs in the Access and Benefit-Sharing Clearing-House (ABSCH) and biodiversity conservation and quality of institutions.

\begin{tabular}{cccccc}
\hline Axes & $\mathbf{1}$ & $\mathbf{2}$ & $\mathbf{3}$ & $\mathbf{4}$ & Total Variance (Inertia) \\
\hline $\begin{array}{c}\text { Eigenvalues } \\
\text { Pseudo-canonical correlations }\end{array}$ & 0.414 & 0.149 & 0.099 & 0.056 & 0.73 \\
Cumulative percentage variance & & 0.832 & 0 & 0 & \\
$\quad \begin{array}{c}\text { of ABS: } \\
\text { ( }\end{array}$ & 57.6 & 78.4 & 92.2 & 100 & \\
of relation ABS-biodiversity and institutions: & 73.5 & 100 & 0 & 0 & 0.72 \\
$\quad$ Sum of all eigenvalues: & & & & & 0.56 \\
Sum of all canonical eigenvalues: & & & & & \\
\hline
\end{tabular}

Source: Authors' elaboration.

In its first two axes, the ordination diagram (Figure 4) shows the general relationship between biodiversity and the conservation thereof, and the quality of institutions in the existence of IRCCs and the type of agreements they represent (commercial, non-commercial, or commercial/non-commercial). The importance of each explanatory variable is revealed by the length of each gradient (arrow) that corresponds to the type of ABS agreement and the site (country). The ordination diagram also shows the dissimilarity between ABS agreements by type of use, demonstrating that there is a significant distance between the three types of agreements.

The correlation between the variables (arrows) is measured by the angle between them. Therefore, it can be seen that there is a correlation between the variables of biodiversity and extension of protected natural areas. The variance inflation factor for these variables was less than 5 , which does not affect the estimates. The variables of biodiversity and extension of protected natural areas correspond to ABS agreements for hybrid commercial/non-commercial use, which are most prevalent in Mexico and Lao People's Democratic Republic. The factors that comprise the quality of institutions variable, namely the efficiency of the legal framework for dispute resolution, relative burden of government regulation, and strength of investor protections, are highly correlated, and they correspond to ABS agreements for commercial use. This type of agreement is most prevalent in India and South Africa. Meanwhile, the property rights variable is most strongly related to ABS agreements for non-commercial use, which are most prevalent in Vietnam, Kenya, Spain, France, Panama, Bulgaria, the Dominican Republic, and Uruguay.

These results suggest that countries could foster the execution of commercial ABS agreements by increasing the efficiency of their respective national legal frameworks for dispute resolution, offering stronger investor protections, and reducing burdensome government regulations. India and South Africa are two of the countries in which the largest number of commercial ABS agreements have been registered in the form of IRCCs in the ABSCH, with 220 and 28, respectively. The existence of hybrid commercial/non-commercial ABS agreements corresponds to higher rates of biodiversity and the existence of conservation policies, as represented in protected natural areas. Mexico, Laos, and India are the only countries for which IRCCs have been registered for this type of ABS agreement.

Finally, non-commercial ABS agreements are associated with the protection of property rights variable. This type of contract commonly included a diverse array of parties, including universities, government research centers, museums, non-governmental organizations, and indigenous groups and local communities. Non-commercial ABS agreements were registered as IRCCs in many of the countries analyzed in this study, including France (123), Spain (43), Kenya (38), Vietnam (28), Panama (19), Peru (5), Bulgaria (3), Guatemala (2), Uruguay (2), the Dominican Republic (1), and Malta (1). 


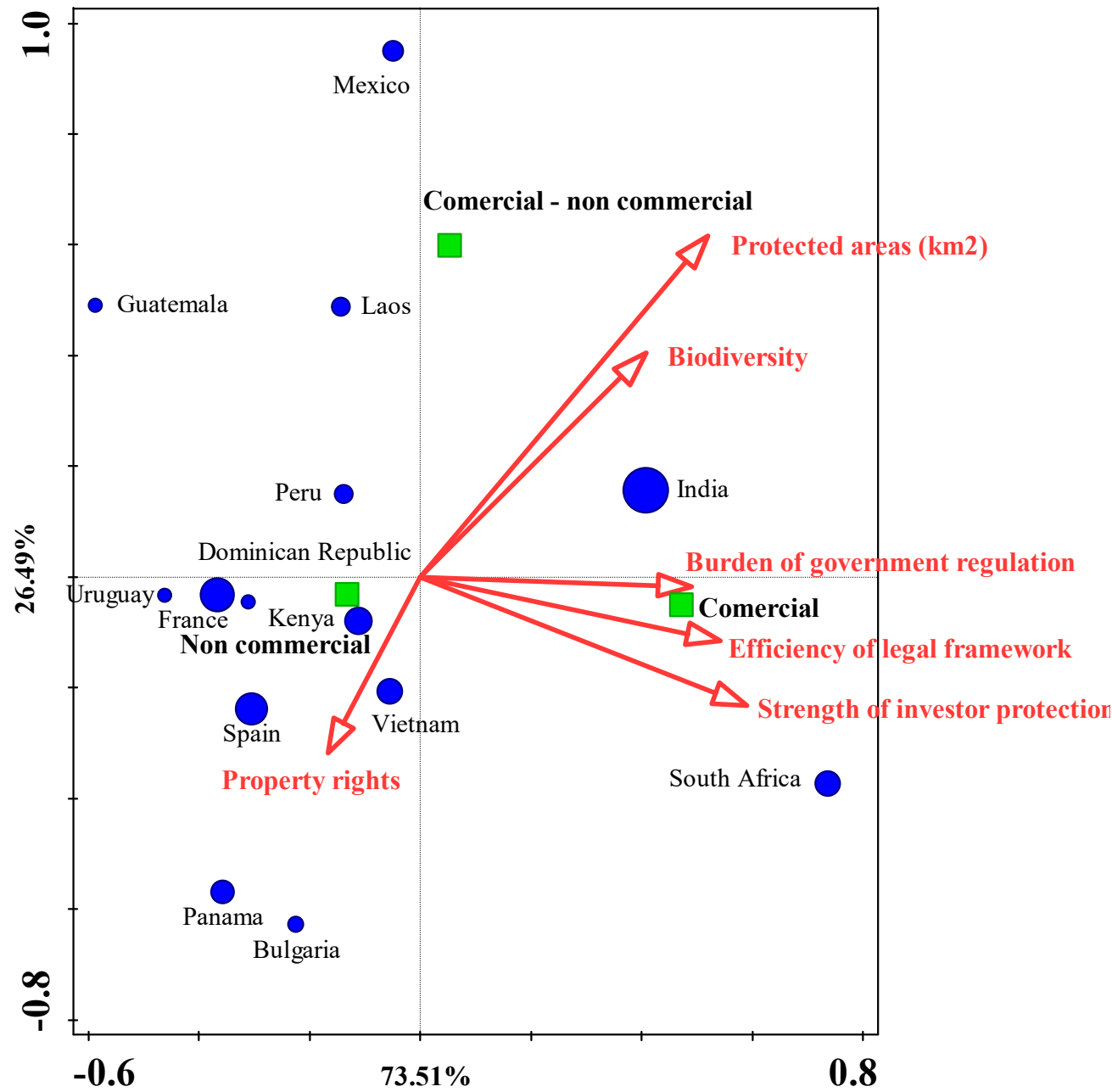

Figure 4. Canonical Correspondence Analysis (CCA) Ordination Graph of IRCCs, Biodiversity, and Quality of Institutions. Source: Authors' elaboration.

\section{Discussion}

Of the 117 countries that had ratified the Nagoya Protocol as of August 2019, IRCCs had been lodged in the ABSCH for only 16 of them. These IRCCs represented ABS agreements that mostly corresponded to the utilization of genetic resources for non-commercial purposes $(64 \%)$, while $35 \%$ of the agreements were for commercial use and a mere $1 \%$ were hybrid, commercial/non-commercial agreements. With these results in mind, we can return to the research questions posed at the outset of this study, namely, what factors explain whether ABS agreements will be concluded in countries that have ratified the Nagoya Protocol? Does the existence of biodiversity conservation policies and the relative abundance of genetic resources favor the execution of ABS agreements? Does the quality of the institutions in a given country explain the utilization of ABS agreements by users and providers of genetic resources and associated traditional knowledge?

Our findings demonstrate that the quality of institutions represents a relevant factor for the conclusion of ABS agreements. Prior studies have shown that the quality of institutions is positively related to economic development [8], and as such, this variable may be understood to constitute an important factor in the utilization of genetic resources for commercial purposes. This is demonstrated in the relationship between the existence of ABS agreements for commercial purposes with the variables of the burden of government regulation, efficiency of the legal framework for dispute resolution, and strength of investor protections. It is notable that higher quality institutions may complement the 
actualization of Articles 13 and 15 of the Nagoya Protocol, which require that member countries establish National Focal Points and Competent National Authorities to govern the domestic ABS system.

Although it may be the case that countries require time following the ratification of the Nagoya Protocol to develop national legislative and regulatory frameworks to implement the treaty, it is also true that these regimes may be enacted relatively quickly, where there exists the political will to do so. Examples of the efficient uptake of the Nagoya system may be found in France and India. The latter country currently has the greatest number of IRCCs registered in the ABSCH (220). This finding may be expected given that India was one of the early adopters of the Nagoya Protocol, which it ratified on 9 October 2012. However, it is notable that France ratified the protocol nearly four years later, on 31 August 2016, and it has the second largest number of IRCCs registered in the ABSCH (153). This indicates that factors other than time alone explain the utilization of the Nagoya Protocol framework by actors in Nagoya Protocol member countries.

Overall, the results of the present study describe certain global trends that help to explain the likelihood that parties will negotiate and execute formal ABS agreements in countries that have ratified the Nagoya Protocol. However, it is important to acknowledge certain limitations that affected our analysis. First, given that the Nagoya Protocol only entered into force less than five years ago, in October 2014, the process of implementation of this regime at the national level in member countries is ongoing. It is likely that many more parties to the Nagoya Protocol will begin to lodge IRCCs in the ABSCH in the near future, a fact that should invite future research. A second limitation was that indicators used to describe the relative richness of traditional knowledge associated with genetic resources, the effect of emerging technologies such as synthetic biology, and the strength of biodiversity governance systems have not yet been developed. It is hoped that future work can elucidate the effect of these and other variables on the implementation of the Nagoya Protocol framework.

\section{Conclusions}

This study is the first to analyze the process of the implementation of the Nagoya Protocol from a global perspective using econometric methods, and specifically a multivariate Canonical Correspondence Analysis. This methodology enabled the identification of certain factors associated with the implementation of the Nagoya Protocol, as measured through the registration of IRCCs in the ABSCH. The results revealed that a relatively high level of biodiversity and the existence of conservation policies in a given country are factors associated with the execution of both commercial and non-commercial ABS agreements between genetic resource providers and users.

The quality of institutions also constituted a relevant factor, with higher quality institutions associated with a greater number of IRCCs lodged in the ABSCH. This variable is also important given the obligations that countries have pursuant to Articles 13 and 15 of the Nagoya Protocol, to establish National Focal Points and Competent National Authorities. Correspondingly, instituting less burdensome government regulations, as well as more efficient legal frameworks for dispute resolution and stronger investor protection, represent strategies that countries can adopt to support the execution of commercial ABS agreements.

As a final point, we recognize that other factors likely affect the implementation of the Nagoya Protocol, as measured by the registration of IRCCs in the ABSCH. These may include the relative richness of local traditional knowledge, the effectiveness of national systems of biodiversity governance, and the relative importance of emerging technologies for the utilization of genetic resources in research and development in a given country. However, these factors were not included within the scope of the present study due to the paucity of information available to investigate these questions at the global level. Nevertheless, the influence of such variables could be assessed in future lines of research. Prospective studies could also questions including the effect of monetary and non-monetary benefit sharing on the well-being of the indigenous groups and local communities that act as providers of genetic resources and associated traditional knowledge. These lines of inquiry would help to substantiate the meaning of "effectiveness" in the implementation of the Nagoya Protocol ABS system. 
Author Contributions: G.A.-P. and L.F.B.-M. developed the idea. D.J.J. and M.A.A.-H. analyzed the data. G.A.-P., L.F.B.-M., D.J.J., and M.A.A.-H. wrote the paper.

Funding: This research was funded by the National Council of Science and Technology of Mexico (CONACYT), Grants numbers PDCPN-2017/6113.

Acknowledgments: We would like to the Northwest Biological Research Center of Mexico (CIBNOR) and for the support provided by Ing. Alejandro Borges Sánchez and MC Ileana Serrano Fraire.

Conflicts of Interest: The authors declare that there is no conflict of interest.

\section{References}

1. Dedeurwaerdere, T.; Melindi-Ghidi, P.; Broggiato, A. Global scientific research commons under the Nagoya Protocol: Towards a collaborative economy model for the sharing of basic research assets. Environ. Sci. Policy 2016, 55, 1-10. [CrossRef]

2. Greiber, T.; Peña, M.S.; Åhrén, M.; Nieto, C.J.; Kamau, C.E.; Cabrera, M.J.; Oliva, M.J.; Perron-Welch, F.; Ali, N.; Williams, C. Guía Explicativa del Protocolo de Nagoya sobre Acceso y Participación en los Beneficios; UICN: Gland, Switzerland, 2013; Volume 18, p. 402.

3. Convention on Biological Diversity. Available online: https://www.cbd.int/convention/text/ (accessed on 2 May 2019).

4. Buck, M.; Hamilton, C. The Nagoya Protocol on Access to Genetic Resources and the Fair and Equitable Sharing of Benefits Arising from their Utilization to the Convention on Biological Diversity. Rev. Eur. Community Int. Environ. Law 2011, 20, 47-61. [CrossRef]

5. Silvestri, L.-C. Protocolo de Nagoya: Desafíos originados a partir de un texto complejo, ambiguo y controversial. Anu. Mexicano Der. Internac. 2017, 17, 697-716. [CrossRef]

6. Kariyawasam, K.; Tsai, M. Access to genetic resources and benefit sharing implications of Nagoya Protocol on providers and users. J. W. Intellect. Prop. 2018, 21, 289-305. [CrossRef]

7. Tsioumani, E. Beyond access and benefit-sharing: Lessons from the law and governance of agricultural biodiversity. J. W. Intellect. Prop. 2018, 21, 106-122. [CrossRef]

8. Acemoglu, D.; Johnson, S.; Robinson, J. Institutions as the Fundamental Cause of Long-Run Growth; National Bureau of Economic Research: Cambridge, MA, USA, 2004.

9. The World Bank. Metadata Glossary. Available online: https://databank.worldbank.org/metadataglossary/ africa-development-indicators/series/GCI.1STPILLAR.XQ (accessed on 8 May 2019).

10. Robinson, D.-F.; Forsyth, M. People, plants, place, and rules: The Nagoya Protocol in Pacific Island countries. Geogr. Res. 2016, 54, 324-335. [CrossRef]

11. Greiber, T. Implementation of the Nagoya Protocol in the European Union and in Germany. Phitomedicine 2019, 53, 313-318. [CrossRef] [PubMed]

12. Bourdy, G.; Aubertin, C.; Jullian, V.; Deharo, E. Quassia "biopiracy" case and the Nagoya Protocol: A researcher's perpective. J. Ethnopharmacol. 2017, 206, 290-297. [CrossRef] [PubMed]

13. Nijar, G.-S.; Louafi, S.; Welch, E.-W. The implementation of the Nagoya ABS Protocol for the research sector: Experience and challenges. Int. Environ. Agreem. Politics Law Econ. 2017, 17, 607-621. [CrossRef]

14. Davis, K.; Smit, M.-F.; Kidd, M.; Sharrock, S.; Allenstein, P. An Access and Benefit-sharing awareness survey for botanic gardens: Are they prepared for the Nagoya protocol? S. Afr. J. of Bot. 2015, 98, 148-156. [CrossRef]

15. Laird, S.A.; Wynberg, R.P. Locating Responsible Research and Innovation Within Access and Benefit Sharing Spaces of the Convention on Biological Diversity: The Challenge of Emerging Technologies. NanoEthics 2016, 10, 189-200. [CrossRef]

16. Löhne, C.; Giere, P.; Neumann, D. Legal and Ethical Challenges: From Collection Management to Access and Benefit-Sharing. In Zoological Collections of Germany; Beck, L., Ed.; Springer: Cham, Switzerland, 2018.

17. Neumann, D.; Borisenko, A.V.; Coddington, J.A.; Häuser, C.L.; Butler, C.R.; Casino, A.; Vogel, J.C.; Haszprunar, G.; Giere, P. Global biodiversity research tied up by juridical interpretations of access and benefit sharing. Org. Divers. Evol. 2018, 18, 1-12. [CrossRef]

18. Comizzoli, P.; William, V.-H. Implications of the Nagoya Protocol for genome resources banks composed of biomaterials from rare and endangered species. Reprod. Fertil. Dev. 2016, 28, 1145-1160. [CrossRef] [PubMed] 
19. Smith, D.; Hinz, H.; Mulema, J.; Weyl, P.; Ryan, M.J. Biological control and the Nagoya Protocol on access and benefit sharing - a case of effective due diligence. Biocontrol Sci. Techn. 2018, 28, 914-926. [CrossRef]

20. Schindel, D.; Bubela, T.; Rosenthal, J.; Castle, D.; du Plessis, P.; Bye, R. The New Age of the Nagoya Protocol. Nat. Conserv. 2015, 12, 43-56. [CrossRef]

21. Robinson, D.F.; Raven, M. Recognising Indigenous customary law of totemic plant species: Challenges and pathways. Geogr. J. 2019, 1-14. [CrossRef]

22. Deplazes-Zemp, A.; Abiven, S.; Schaber, P.; Schaepman, M.; Schaepman-Strub, G.; Schmid, B.; Shimizu, K.J.; Altermatt, F. The Nagoya Protocol could backfire on the global South. Nat. Ecol. Evol. 2018, 2, 917. [CrossRef] [PubMed]

23. Convention on Biological Diversity 2019, Annex 1: Biodiversity Information by Country. Available online: https://www.cbd.int/gbo1/annex.shtml (accessed on 10 May 2019).

24. Convention on Biological Diversity 2019, Access and Benefit-Sharing Clearing-House. Available online: https://absch.cbd.int/ (accessed on 13 May 2019).

25. Cytoscape, version 3.7.1. In Network Data Integration, Analysis and Visualization in Box; The Cytoscape Consortium: San Diego, CA, USA, 2019.

26. Ter Braak, C. Canonical correspondence analysis: A new eigenvector technique for multivariate direct gradient analysis. Ecology 1986, 67, 1167-1179. [CrossRef]

27. Beltrán-Morales, L.-F.; García-Rodríguez, F.; Borges Contreras, J.; Sánchez-Mota, G.; Ortega Rubio, A. Environmental and socioeconomic multivariate analysis of the primary economic sector of Mexico. Sustain. Dev. 2003, 11, 77-83. [CrossRef]

28. Beltrán Morales, L.-F.; García-Rodríguez, F.; Borges Contreras, J.; Urciaga García, J.; Ortega Rubio, A. Economy and Environmental Problems in the Mexican Coastal States. Econ. Mex. 2006, 15, 327-339.

29. Leps, J.; Smilauer, P. Multivariate Analysis of Ecological Data using CANOCO; Cambridge University Press: New York, NY, USA, 2003.

(C) 2019 by the authors. Licensee MDPI, Basel, Switzerland. This article is an open access article distributed under the terms and conditions of the Creative Commons Attribution (CC BY) license (http://creativecommons.org/licenses/by/4.0/). 